\title{
Global trends in AIDS mortality
}

John Bongaarts

Population Council

Francois Pelletier

Patrick Gerland

Follow this and additional works at: https://knowledgecommons.popcouncil.org/departments_sbsr-pgy

Part of the Demography, Population, and Ecology Commons, Health Policy Commons, Immune System Diseases Commons, International Public Health Commons, Medicine and Health Commons, and the Virus Diseases Commons How does access to this work benefit you? Let us know!

\section{Recommended Citation}

Bongaarts, John, Francois Pelletier, and Patrick Gerland. 2009. "Global trends in AIDS mortality," Poverty, Gender, and Youth Working Paper no. 16. New York: Population Council. Version of record: https://doi.org/ 10.1007/978-90-481-9996-9_8 


\section{POVERTY, GENDER, AND YOUTH}

\section{Global Trends in AIDS Mortality}

John Bongaarts, François Pelletier, and Patrick Gerland

WORKING PAPER NO. 162009

$\mathcal{Q}$ Population Council 


\section{(2) Population Council}

One Dag Hammarskjold Plaza

New York, New York 10017 USA

www.popcouncil.org

pubinfo@popcouncil.org

For information on Poverty, Gender, and Youth working papers, see www.popcouncil.org/publications/wp/index.html

This material may not be reproduced without written permission from the authors.

ISSN: $1554-8538$

(C) 2009 The Population Council, Inc. 


\title{
Global Trends in AIDS Mortality
}

\author{
John Bongaarts \\ François Pelletier \\ Patrick Gerland
}

\begin{abstract}
The views and opinions expressed in this paper are those of the authors and do not necessarily reflect those of the United Nations.

John Bongaarts is Vice President and Distinguished Scholar, Population Council, New York. François Pelletier is Chief of the Mortality Section, Population Division, United Nations, New York. Patrick Gerland is Population Affairs Officer, Population Policy Section, Population Division, United Nations, New York.

The authors are grateful to Mr. Thomas Buettner, Assistant Director of the Population Division, for kindly updating the Population Division's AIDS program and designing queries that enabled the production of special tabulations, which were used in this study; the authors would also like to thank all other staff members of the Population Division who worked on the 2008 Revision of World Population Prospects: Mr. Gerhard Heilig, Mr. Kirill Andreev, Mr. Taeke Gjaltema, Ms. Vladimira Kantorova, Mr. Pablo Lattes, and Mr. Nan Li. The authors also wish to thank Ms. Hania Zlotnik, Director of the Population Division, for her insightful comments.
\end{abstract}

Chapter prepared for International Handbook of Adult Mortality (Richard G. Rogers and Eileen M. Crimmins, editors) Springer. 


\begin{abstract}
This paper reviews the evolution of the HIV/AIDS epidemic and provides estimates of past trends and future projections of AIDS mortality indicators, including numbers of AIDS deaths, the proportion of all deaths that are due to AIDS, and life expectancy. In 2007, a total of 2.0 million men, women, and children died of AIDS worldwide. The death toll will remain high in the future because 33 million individuals are currently infected and about 2.7 million new HIV infections occur each year. A cumulative total of 24 million people have died from AIDS between 1980 and 2007, and by 2030 this total is projected to reach 75 million. Despite the rapid spread of this new disease during the 1980s and 1990s, the epidemic has reached a major turning point in recent years as the rate of new infections peaked and began a decline. Worldwide, the proportion of all deaths caused by AIDS reached 3.9 percent in 2004. This proportion varies widely from a high of 15 percent in sub-Saharan Africa to around one percent in Asia and other regions. In the future, the number of AIDS deaths and the proportion of deaths due to AIDS are projected to remain approximately at their current levels.
\end{abstract}


The global HIV/AIDS ${ }^{1}$ pandemic is one of the deadliest epidemics of modern times. In 2007, a total of 2.0 million men, women, and children died of AIDS worldwide. The death toll will remain high in the future because 33 million individuals are currently infected and about 2.7 million new HIV infections occur each year (UNAIDS 2008). Most of these currently and newly infected individuals are likely to die of AIDS eventually, despite the increasing availability of antiretroviral treatment (ART).

Although the HIV virus has reached all corners of the globe, the sizes of epidemics vary widely among countries (UNAIDS 2008). In 2007, HIV prevalence (measured as the percent of adults aged 15-49 who are currently infected) in world regions outside sub-Saharan Africa averaged a fraction of one percent. In contrast, prevalence in sub-Saharan Africa was 5.0 percent - an order of magnitude larger than in the rest of the world (see Figure 1). Even larger differences in epidemics exist within sub-Saharan Africa, where prevalence levels range from less than one percent in a few countries in Western Africa to above 15 percent in parts of Eastern and Southern Africa. Worldwide, approximately 0.8 percent of adults are infected with HIV.

This huge variation in epidemic sizes is partly explained by the fact that HIV is not a particularly infectious agent in heterosexual relationships, which is the dominant mode of transmission in many countries. On average, in low-income countries the risk of transmission per act between an infected man or woman and his or her uninfected heterosexual partner is about 34 per 1000 in the absence of commercial sex exposure (Boily et al. 2009). This low transmission risk prevents large epidemics in most populations. The exceptions are populations in which a substantial proportion of the population engages in high-risk sexual behavior (i.e. frequent change of partners and multiple concurrent partners), especially if — as in Southern Africa — male circumcision is limited, the use of condoms is low, and additional risk factors such as other sexually transmitted infections (STIs) and genital ulcers are present (Bongaarts et al. 2008; Caldwell 2000; Halperin and Epstein 2004, 2007; Powers et al. 2008; Shapiro 2002).

This paper begins with a summary of data sources and then reviews the evolution of the epidemic over time. This is followed by a summary of the dynamics of HIV infection and mortality from AIDS. The second part of the paper describes past trends and future projections in AIDS mortality indicators, including numbers of AIDS deaths, the proportion of all deaths that are due to AIDS, and life expectancy.

\section{DATA}

Estimates of HIV prevalence and incidence and AIDS mortality from 1980 to 2007 and projections from 2008 to 2030 were calculated for 58 countries by the United Nations Population Division as part of the preparation of the 2008 Revision of World Population Prospects (United Nations 2009a). The starting points for these calculations are estimates of country-specific HIV prevalence for selected years provided by UNAIDS (2008). Annual estimates and projections of prevalence are obtained by refitting UNAIDS estimates and extrapolating them using a model developed by the UNAIDS Reference Group on Estimates, Modelling, and Projections (Brown et al. 2008; Ghys et al. 2008; UNAIDS Reference Group 2002) that was adopted and customized by the Population Division for its own needs. Further details on the projection methodology and assumptions are provided by the United Nations (2006, 2009b). Once trends in HIV prevalence 
are established, the model calculates HIV incidence as well as deaths attributable to AIDS. These estimates and projections are made for the same set of 58 countries, which includes all countries with HIV prevalence above one percent as well as very populous countries with lower prevalence (China, India, the United States, the Russian Federation, and Brazil). For those 58 countries, which accounted for 93.2 percent of all AIDS deaths in 2007, information by age for different indicators and events, including deaths, is available by calendar year.

To obtain global estimates of AIDS deaths at the world and regional levels, estimates for all other countries for the period 1980-2007 produced by UNAIDS (2008) ${ }^{2}$ were used and added to the estimates for the 58 countries. The projection of AIDS deaths at aggregated levels for the period 2008-2030 is based mainly on the 58 country-specific projections and assumes that the proportion of AIDS deaths that occurred in those countries in 2007 at the world level (that is 93.2 percent) remains constant in the future (a similar assumption is made at the regional level, though the proportion of AIDS deaths varies by region). Consequently, the projected numbers of AIDS deaths presented worldwide are based on the 58 countries adjusted by a factor of 1.073 to account for AIDS deaths in other countries.

\section{THE EVOLUTION OF THE EPIDEMIC}

HIV prevalence levels from 1975 to 2030 are plotted in Figure 2, Panel A for selected non-African countries and in Panel B for selected African countries. The vertical line in this and other figures separates estimates up to 2007 and projections from 2008 onward. The epidemics in sub-Saharan African countries in Panel B are all larger than those in countries in other continents in Panel A (note the difference in scales on the vertical axes of these figures). Epidemics also started at different times-for example, the ones in the United States and Uganda started relatively early and the ones in the Russian Federation and South Africa relatively late. Despite these differences, the general shapes of the prevalence patterns are broadly similar. Epidemics initially spread slowly, are followed by a period of rapid expansion, and end with a plateau. In a number of countries, a significant decline started before 2007. Nearly all epidemics reached their plateau in the 1990 s or the early 2000 s.

The appearance of recent plateaus is one of the epidemic's most interesting and important features. A stable or declining infection level implies that the virus is present in a proportion of the population yet is not spreading any further. There are several explanations for such an unexpected development (Bongaarts et al. 2008; Potts et al. 2008; Shelton et al. 2006).

First, high-risk behavior has declined in a number of countries, in part because of prevention programs that encourage abstinence, sexual fidelity, and condom use and that discourage needle sharing. For example, in Uganda, following a vigorous campaign that started in the late 1980s, HIV prevalence declined by about half. There is strong evidence that behavioral change contributed to this decline, and both men and women have reported a reduction in sex with non-regular partners and a rise in condom use (Stoneburner and Low-Beer 2004). Declines in high-risk behavior and infection rates have also occurred in Kenya, Malawi, Thailand, and Zimbabwe (UNAIDS 2006, 2007, 2008).

A second explanation for the decline in HIV prevalence is that epidemics have reached their natural limits. Every population consists of a heterogeneous mixture of subgroups with 
widely varying infection risks. Sex workers and their clients, needle-sharing intravenous drug users (IDUs), and homosexual men are at relatively high risk, while men and women living in monogamous unions or without sexual partners are at low risk. At the onset of an epidemic, the virus quickly invades the highest-risk groups, but then encounters resistance when the pools of high-risk and most-susceptible individuals are infected or die out. ${ }^{3}$ The epidemic reaches a plateau when the virus has achieved maximum penetration of the vulnerable subgroups. This point seems to have been reached in most countries by the early 2000s. In the United States and Europe, for example, parts of the homosexual and IDU groups are at relatively high risk of infection, but infection risks are much lower for the vast majority of heterosexuals. As a result, HIV prevalence among heterosexuals in these regions is a fraction of one percent. In contrast, Southern African populations have relatively large high-risk groups of sex workers and their partners, and the virus spreads more readily among the general population through diffuse networks of multiple and concurrent sexual partners (Halperin and Epstein 2004, 2007). The overall size of a country's epidemic depends on the sizes of the different risk groups and their behaviors (i.e. frequency of partner change, condom use), biological characteristics (e.g. male circumcision), and the prevalence of other STIs.

A third contributing factor is that the initial wave of infections in the epidemic leads about a decade later to a wave of AIDS deaths (in the absence of ART). These deaths remove infected individuals from the population (and from the numerator of the HIV prevalence rate), thus contributing to plateaus or declines in prevalence levels.

It is not possible to quantify precisely the roles of any of the factors outlined above. Behavioral change is likely to have occurred in countries where HIV prevalence is declining, but epidemics can also reach a plateau without significant behavioral change when the epidemic runs its natural course.

\section{THE DYNAMICS OF HIV INFECTIONS AND AIDS DEATHS}

The preceding analysis relied on HIV prevalence rates to assess epidemic trends. HIV prevalence is the most widely available indicator of epidemic size and it is readily interpreted. But prevalence is a lagging indicator of HIV infections. The numerator of the HIV prevalence rate consists of all currently infected adults (15-49), regardless of the time when they became infected. Because in the absence of ART individuals survive about a decade after infection, the estimated prevalence in a given year is determined by the number of infections that occurred in the past decade or earlier. The HIV incidence rate (i.e. the annual rate of new infections among adults aged 15-49) is therefore a better indicator to track epidemic trends. The total infected population at a point in time is the net result of past additions to the infected population through new infections and subtraction through deaths. The incidence rate measures the rate of new additions to the pool of infected individuals.

Figure 3 presents estimates of incidence rates (solid lines) for Botswana and Uganda, two countries with large epidemics. As mentioned before, HIV incidence typically rises rapidly in the initial years of the epidemic, followed by a peak and then a large but slower decline. As expected, the peaks in incidence in Botswana (46 per 1000 per year) and Uganda (31 per 1000 per year) are more than an order of magnitude higher than the peaks in countries in other 
continents. The timing of the peaks in incidence also varies significantly. The first occurred in the United States and in Uganda in the mid 1980s. The ongoing declines in incidence in most countries are caused by the same factors noted above for prevalence trends: saturation of highrisk groups and changes in high-risk behavior. But there is an additional third factor: a decline in the average infectiousness of infected individuals because fewer are in the acute post-infection stage and because of higher levels of ART. Note that the peaks in incidence seen in Figure 3 occurred several years before the peaks in prevalence shown in Figure 2, Panel B.

In the absence of treatment, HIV disease runs its natural course, which means that in infected people the infection is followed by a period of years in which few symptoms are present before the onset of AIDS and then death. The distribution of the survival interval from infection to death has a mean of 11 years for males, 12 years for females, and a rather large variance. Some individuals die shortly after infection, about half die within the first 11 years, and one in four survive more than 15 years even without treatment.

Figure 3 includes the estimated and projected trends in death rates because of AIDS (AIDS deaths per 1,000 population aged 15-59 as dashed lines). Note that the peaks in the death rates occur about a decade after the peaks in the incidence rates. The peaks in death rates are also lower in magnitude than the corresponding peaks in incidence rates because survival times between infection and death from AIDS vary substantially among individuals, and because treatment reduces death rates. The trajectory of the AIDS death rate in Botswana shows a sudden decline between 2003 and 2006. This decline is largely attributable to a very rapid increase in the availability and use of ART during and shortly before this period.

As expected, the AIDS death rate of a country depends on the size of the HIV epidemic. Figure 4 plots the AIDS death rate in 2005-2010 by HIV prevalence in 2000 for 58 countries. The correlation is high $\left(\mathrm{R}^{2}=0.91\right)$, but still below one. Countries with high levels of ART (e.g. Botswana and Namibia) tend to have lower than expected death rates for a given level of prevalence because treatment suppresses the disease.

\section{TRENDS IN AIDS MORTALITY}

The UN projection model provides detailed country-level estimates of AIDS deaths and mortality rates by age and sex from 1980 to 2030 for the 58 countries for which the demographic impact of the HIV/AIDS epidemic was estimated and projected explicitly. To simplify the presentation below, only selected findings for both sexes combined are presented. Except for Figure 5, which encompasses global estimates, all other findings are based on the estimates and projections provided by the United Nations Population Division.

\section{AIDS deaths}

Panel A of Figure 5 plots the estimated and projected global number of AIDS deaths from 1980 to 2030. This number rose from near zero in 1980 to 2.1 million in 2007, with a peak at 2.2 million in 2005. The estimate for 2007 is virtually the same as that provided by UNAIDS ( 2.0 million with a range of 1.8 million to 2.3 million). The projection indicates only a slight rise in the global number of AIDS deaths, reaching a maximum value of 2.36 million in 2030 . A notable feature of the global projection is the modest fluctuations in the future number of AIDS 
deaths. The initial decline in AIDS deaths starting around 2006 is partly related to the ongoing intensive global effort to provide ART to increasing proportions of AIDS patients. However, AIDS deaths subsequently rise again because of the postponement of deaths related to treatment and the occurrence of new infections; a changing population size and age distribution may also contribute to these fluctuations.

The noticeable inflection point in 2015 and the subsequent increase in the number of AIDS deaths are also partly related to assumptions made with respect to future treatment coverage levels. The proportion of the HIV-positive adult population receiving treatment in each country is consistent with estimates prepared by the World Health Organization (WHO/UNAIDS/UNICEF 2008), which averaged 36 percent in 2007 among the 58 countries, with country levels ranging from 8 percent to 99 percent. The projected coverage levels for the treatment of adults are expected to increase substantially and reach on average 64 percent for the 58 affected countries, with country levels ranging from 40 percent to 99 percent by 2015 . However, coverage levels are then assumed to remain constant until 2030 at the level reached in each country in 2015. The assumptions made for treatment coverage levels as well as for other parameters in modeling the demographic impact of the 58 countries most affected by the HIV/AIDS epidemic have major bearing on the projected number of AIDS deaths at the world and regional levels.

The number of AIDS deaths varies widely by region, with the largest number in subSaharan Africa (see Panel A, Figure 5). In 2007 an estimated 1.5 million AIDS deaths occurred in sub-Saharan Africa, which represent 72 percent of the global total. In the rest of the world, which contains nearly 9 out of 10 of the world's people, the number of AIDS deaths is estimated at 0.6 million (mostly in Asia).

Panel B of Figure 5 plots the proportion of all deaths that are attributable to AIDS for the world, as well as for sub-Saharan Africa and Asia. For the world as a whole, this proportion peaked in 2004 at 3.9 percent. As expected, the proportion is much higher in sub-Saharan Africa (15 percent in 2004) than in the rest of the world (1.2 percent in Asia and 1.1 percent in other regions). The global proportion is expected to decline modestly to 3.3 percent by 2030 .

\section{AIDS deaths by age}

AIDS deaths are concentrated among young adults and children. The reason for the large impact of the epidemic among young adults is that sexual intercourse is the dominant mode of HIV transmission. The secondary mode of transmission, from infected mother to infant around the time of birth, leads to substantial infection levels among infants, particularly in countries where fertility is high and treatment of pregnant women is lacking.

In 2007 an estimated 86 percent of AIDS deaths occurred among adults aged 15-59 in the 58 countries included in the UN projections (see Figure 6, Panel A). In contrast, only 14 percent of AIDS deaths occurred in age group 0-14 and 0.4 percent in age group 60 and over. By 2030 only a slight change in the proportion of AIDS deaths at ages 15-59 (to 91 percent) is expected, but the proportions under age 15 and over age 60 are expected to decline and rise, respectively. Three factors are responsible for the projected decline in the proportion under age 15: a rise in 
prevention of mother-to-child transmission of HIV (PMTCT), expanded access to ART treatment of pregnant mothers and infected children, and a decline in fertility.

The proportion of all deaths due to AIDS is much higher among adults aged 15-59 than in other age groups. As shown in Figure 6, Panel B, this proportion reached 5.6 percent for all ages combined in 2004, but equaled 16 percent in age group 15-59, and just 3.2 percent for age group 0-14. This finding is explained by the concentration of AIDS deaths among young adults, combined with the fact that death rates from other causes are very low in this age group.

As shown in Figure 7, the proportion of deaths due to AIDS among adults aged 15-59 has reached very high levels in a few countries in sub-Saharan Africa (e.g. 85 percent in Botswana in 2003 and 61 percent in Uganda in 1996). These two countries have very large epidemics, and by African standards they have a relatively high quality of healthcare, so that their death rates from other causes are relatively low. In contrast, in many countries outside sub-Saharan Africa, the proportion of deaths attributable to AIDS is typically well below 10 percent.

The projections to 2030 suggest that the proportion of AIDS deaths at ages 15-59 will remain approximately at current levels for the 58 countries combined (see Figure 6, Panel B). The same is true in many individual countries, as shown in Figure 7. The exceptions to this general trend are countries with relatively rapid declines in HIV incidence, which are expected to see future declines in proportions of deaths due to AIDS (e.g. in Uganda).

\section{LiFE EXPECTANCY AT AgE 15}

Life expectancy at age 15 (denoted $e_{15}$ ) is a widely used and easily interpretable indicator of adult mortality; it represents the average number of additional years that individuals reaching their fifteen birthday expect to live. The epidemic's impact on this indicator can be assessed by comparing the "AIDS" and "No-AIDS" scenarios prepared by the United Nations Population Division as part of its 2008 Revision of World Population Prospects (United Nations 2009a). The AIDS scenario incorporates the impact of the HIV/AIDS epidemic since its inception in the 1980s. In the No-AIDS scenario, the mortality rates of uninfected individuals are applied to the entire population, leading to a hypothetical scenario of what the mortality in each country would have been in the absence of AIDS.

Estimates of $e_{15}$ from 1980 to 2007 and projections from 2008 to 2030 are plotted in Figure 8 for selected non-African (Panel A) and African countries (Panel B). The net reduction in $e_{15}$ caused by the epidemic (i.e. the difference between the No-AIDS and AIDS scenarios) is plotted in Figure 9. According to these results, the epidemic's impact on $e_{15}$ in the non-African countries has been relatively modest - around one year or less in 2005-2010 (the large decline in $e_{15}$ in the Russian Federation between the late 1980s and the early 2000s is unrelated to the HIV/AIDS epidemic). In contrast, a much larger impact is evident in African countries. For example, in Botswana in 2000-2005 the epidemic reduced $e_{15}$ by 17.8 years, from 56.6 in the NoAIDS scenario to 38.9 years in the AIDS scenario. As previously noted, the modest rebound in $e_{15}$ in recent years in Botswana is due to the wider availability and use of ART.

As was the case for the AIDS death rate, a country's reduction in $e_{15}$ caused by AIDS mortality varies directly with the size of the HIV epidemic. Figure 10 plots the decline in $e_{15}$ in 2005-2010 by HIV prevalence in 2000 for all 58 countries. The small proportion of the variance 
not explained by the regression $\left(\mathrm{R}^{2}=0.96\right)$ is largely due to the mortality-reducing effect of ART in countries with high ART coverage (e.g. Botswana and Namibia).

\section{CONCLUSION}

Based on our estimates, a cumulative total of 24 million people have died from AIDS between 1980 and 2007, and by 2030 this cumulative total is projected to reach 75 million. This pandemic is one of the most serious epidemics of modern times, and the eventual death toll will substantially exceed the toll from the 1918 influenza epidemic. In 2004, HIV/AIDS was the sixth leading cause of death at the world level and the fourth leading cause in low-income countries, after lower respiratory infections, ischemic heart disease, and diarrheal diseases (WHO 2008).

Despite these grim statistics and the exceedingly rapid spread of this new disease during the 1980s and 1990s, the epidemic has reached a major turning point in recent years as the incidence of new infections peaked and began to decline. Several factors were responsible for this turnaround, including a reduction in high-risk behavior, the natural limits of the epidemic, and a decline in the infectiousness of people living with HIV. The peak in new infections is followed by a peak in death rates about a decade later because of the long average interval between infection and the onset of AIDS. Our estimates indicate that the global number of new HIV infections peaked in the mid-1990s and the number of AIDS deaths peaked at 2.16 million in 2005. Worldwide, the proportion of all deaths that are caused by AIDS reached 3.9 percent in 2004. This proportion varies widely from a high of 15 percent in sub-Saharan Africa to around one percent in Asia and other regions. In the future, the number of AIDS deaths and the proportion of deaths due to AIDS are projected to remain approximately at their current levels. Modest fluctuations may occur partly because of the rapidly spreading availability of treatment, which initially delays deaths, pushing them to later years. Fluctuations also arise because of the assumptions made with respect to future coverage levels of treatment. The size and age composition of the population are also partly responsible for the projected trends in the number of AIDS deaths.

The AIDS epidemic's impact on life expectancy at age 15 is less than a year in much of the world outside Africa but has amounted to over 10 years in Southern Africa. Projections indicate that life expectancies with AIDS will increase for nearly all countries from their current depressed levels. The impact of AIDS on $e_{15}$ is expected to remain approximately at current levels until 2030 except in a few countries (e.g. Uganda and Zimbabwe) where the epidemic is declining substantially.

These projections depend on the assumptions underlying them, and further interventions - in particular, prevention efforts - could reduce the number of AIDS deaths to lower levels. Uncertainty regarding the accuracy of the estimates of past trends in HIV prevalence, incidence, and AIDS deaths, as well as an incomplete understanding of the dynamics of the epidemic and its behavioral and biological determinants, makes any projections tentative. The difficulty of predicting future trends in behavior, prevention efforts, and affordable access to treatment must also be considered. Further research on these issues is essential to improve the accuracy of medium-term projections. 


\section{NOTES}

1 HIV is the Human Immunodeficiency Virus responsible for the Acquired Immune Deficiency Syndrome (AIDS), which left untreated results in premature death.

2 For some countries and for specific periods, estimates extracted from Spectrum files were also used. For consistency purposes, slight prorating adjustments were also made when deemed necessary.

3 Assuming the presence of proper screening of blood supply and organ donors from highrisk groups to prevent non-sexual transmission to the general population through medical procedures.

\section{REFERENCES}

Boily, M.C, R.F. Baggaley, L. Wang, B. Masse, R. White, R. Hayes, and M Alary. 2009. "Heterosexual Risk of HIV-1 Infection Per Sexual Act: Systematic Review and Metaanalysis of Observational Studies." The Lancet Infectious Diseases 9(2):118-29.

Brown, T., J.A. Salomon, L. Alkema, A.E. Raftery, and E. Gouws. 2008. "Progress and Challenges in Modelling Country-Level HIV/AIDS Epidemics: The UNAIDS Estimation and Projection Package 2007. Sexually Transmitted Infections August 2008, Volume 84, Supplement 1, pp. i5-i10. doi:10.1136/sti.2008.030437 - http://sti.bmj.com/cgi/content/ full/84/Suppl_1/i5

Bongaarts, J., T. Buettner, G. Heilig, and F. Pelletier. 2008. "Has the AIDS epidemic peaked?" Population and Development Review 34(2): 199-224.

Caldwell, J.C. 2000. "Rethinking the African AIDS Epidemic." Population and Development Review 26(1):117-35.

Ghys, P.D., N. Walker, W. McFarland, R. Miller, and G.P Garnett. 2008. "Improved Data, Methods and Tools for the 2007 HIV and AIDS Estimates and Projections." Sexually Transmitted Infections. August 2008, 84, Supplement 1: i1-i4;doi:10.1136/sti.2008. 032573 - http://sti.bmj.com/cgi/content/full//84/Suppl_1/i1

Halperin, D.T. and H. Epstein. 2004. "Concurrent Sexual Partnerships Help to Explain Africa's High HIV Prevalence: Implications for Prevention." The Lancet 364(9428):4-6.

- 2007. "Why is HIV Prevalence So Severe in Southern Africa?" The Southern African Journal of HIV Medicine (March):19-24.

Potts, M., D.T. Halperin, D. Kirby, A. Swidler, E. Marseille, J.D. Klausner, N. Hearst, R.G. Wamai, J.G. Kahn, and J. Walsh. 2008. "Reassessing HIV Prevention" Science 320(5877):749-50. 
Powers, K.A., C. Poole, A.E. Pettifor, and M.S. Cohen. 2008. "Rethinking the Heterosexual Infectivity of HIV-1: A Systematic Review and Meta-Analysis." The Lancet Infectious Diseases. 8(9):553-63.

Shapiro, R. 2002. "Drawing Lines in the Sand: The Boundaries of the HIV Pandemic in Perspective." Social Science and Medicine 55:107-10.

Shelton, J.D., D.T. Halperin, and D. Wilson. 2006. “Has Global HIV Incidence Peaked?” Lancet 367(9517): 1120-21.

Stoneburner, R.L. and D. Low-Beer. 2004. "Population-Level HIV Declines and Behavioral Risk Avoidance in Uganda." Science 304: 714-718 (30 April).

UNAIDS Reference Group on Estimates, Modelling, and Projections. 2002. "Improved Methods and Assumptions for Estimation of the HIV/AIDS Epidemic and its Impact: Recommendations of the UNAIDS Reference Group on Estimates, Modeling and Projections." AIDS 16:W1-W14.

UNAIDS. 2006. "Report on the Global AIDS Epidemic." Joint United Nations Programme on HIV/AIDS. Geneva: UNAIDS.

—. 2007. "AIDS Epidemic Update: December 2007.” Joint United Nations Programme on HIV/AIDS (UNAIDS) and World Health Organization (WHO). Geneva: UNAIDS.

—. 2008. "2008 Report on the Global AIDS Epidemic." Joint United Nations Programme on HIV/AIDS (UNAIDS) and World Health Organization (WHO). Geneva: UNAIDS. See online tables: "Adult (15-49) HIV prevalence percent by country, 1990-2007 (with 95 percent confidence intervals)"; and "AIDS deaths in adults and children by country, 1990-2007".

http://data.unaids.org/pub/GlobalReport/2008/080813_gr08_prev1549_1990_2007_en.xls.

http://data.unaids.org/pub/GlobalReport/2008/080818_gr08_deaths_1990_2007_en.xls.

United Nations, Department of Economic and Social Affairs, Population Division. 2006. World Population Prospects: The 2004 Revision, vol. III, Analytical Report (United Nations publication, Sales No. E.05.XIII.7).

- 2009a. World Population Prospects: The 2008 Revision, CD-ROM Edition-Extended Dataset in Excel and ASCII formats (United Nations publication, ST/ESA/SER.A/283; special tabulations were prepared for this study).

2009b. Assumptions underlying the results of the 2008 revision of World Population Prospects - http://esa.un.org/unpp/index.asp?panel=4. 
World Health Organization. 2008. "The Global Burden of Disease: 2004 Update." Geneva: WHO: http://www.who.int/healthinfo/global_burden_disease/GBD_report_2004update_ part2. pdf

WHO/UNAIDS/UNICEF. 2008. Towards universal access: scaling up priority HIV/AIDS interventions in the health sector, progress report 2008. Geneva, WHO, June 2008 http://www.who.int/entity/hiv/pub/towards_universal_access_report_2008.pdf 
Figure 1. HIV Prevalence in 2007 among Adults Aged 15-49

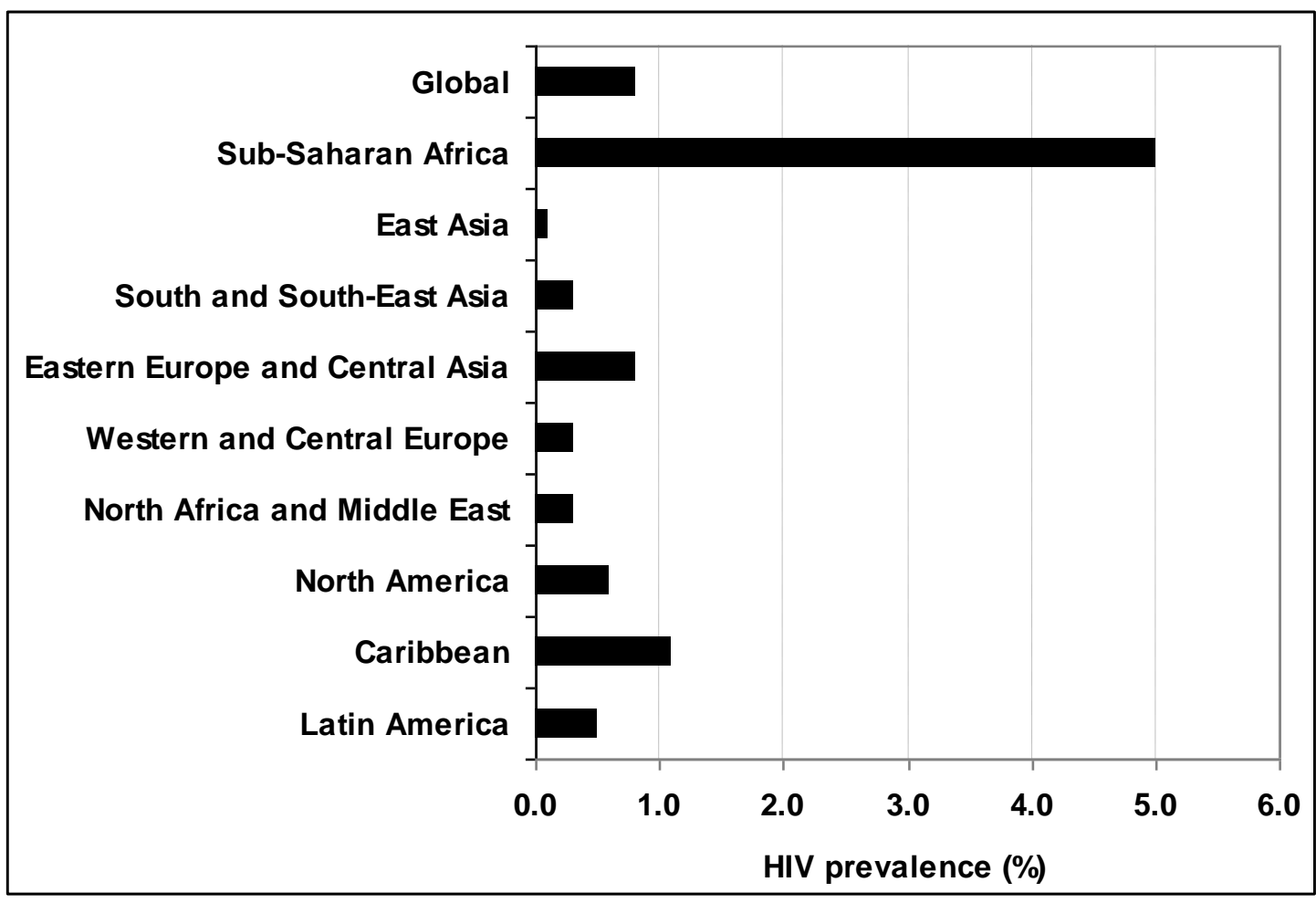

Source: UNAIDS 2008. 
Figure 2. Estimated and Projected Prevalence of HIV, 1975-2025

A. Selected Non-African Countries

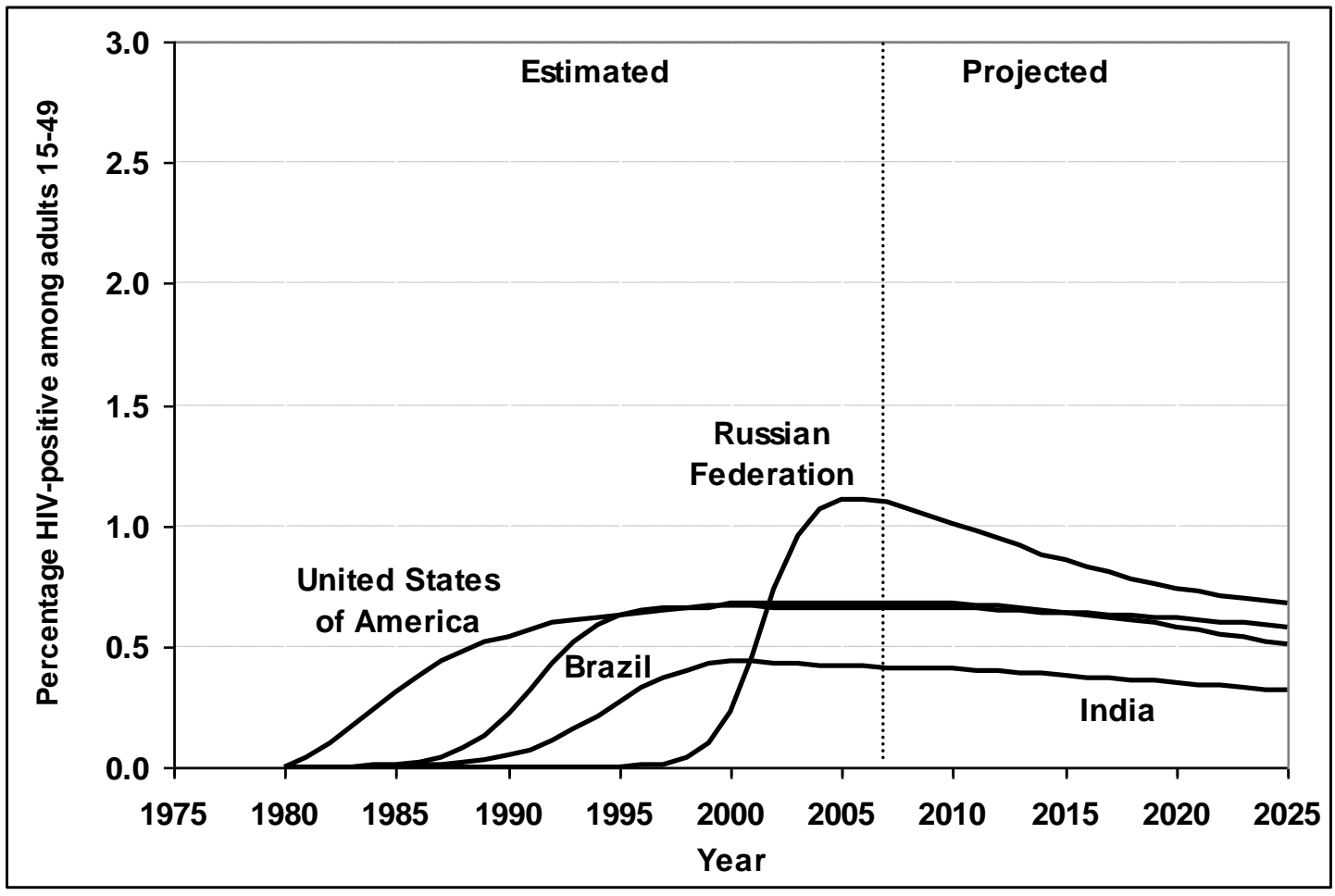

B. Selected African Countries

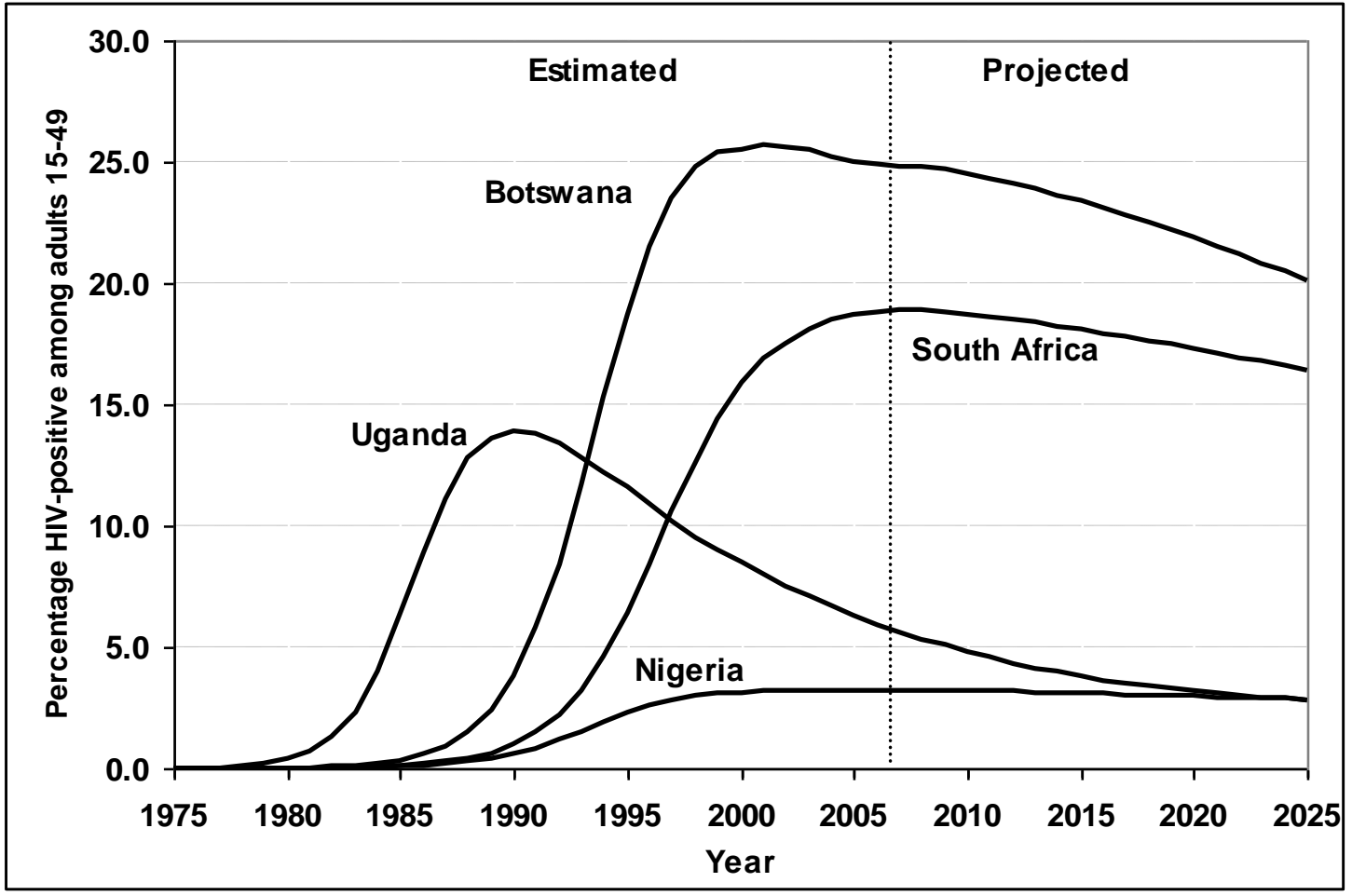

Source: United Nations 2009a (special tabulations) 
Figure 3. HIV Incidence Rate in Population 15-49 (per 1000) and AIDS Death Rates in Ages 15-59 (per 1000), Uganda and Botswana, 1975-2030

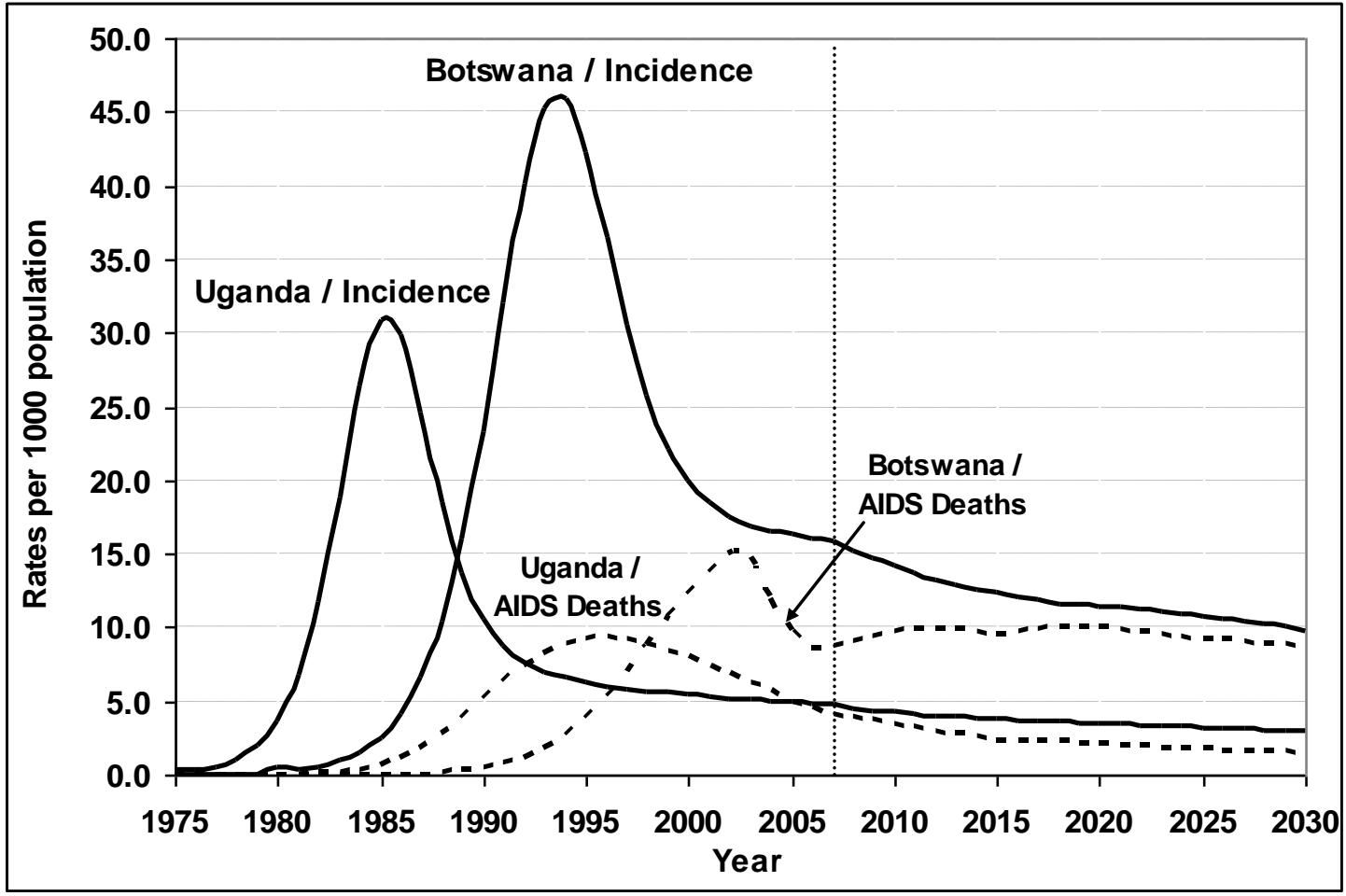

Source: United Nations 2009a (special tabulations).

Figure 4. AIDS Death Rates in Ages 15-59 during 2005-2010 by

HIV Prevalence Levels among Adults Aged 15-49 in 2000

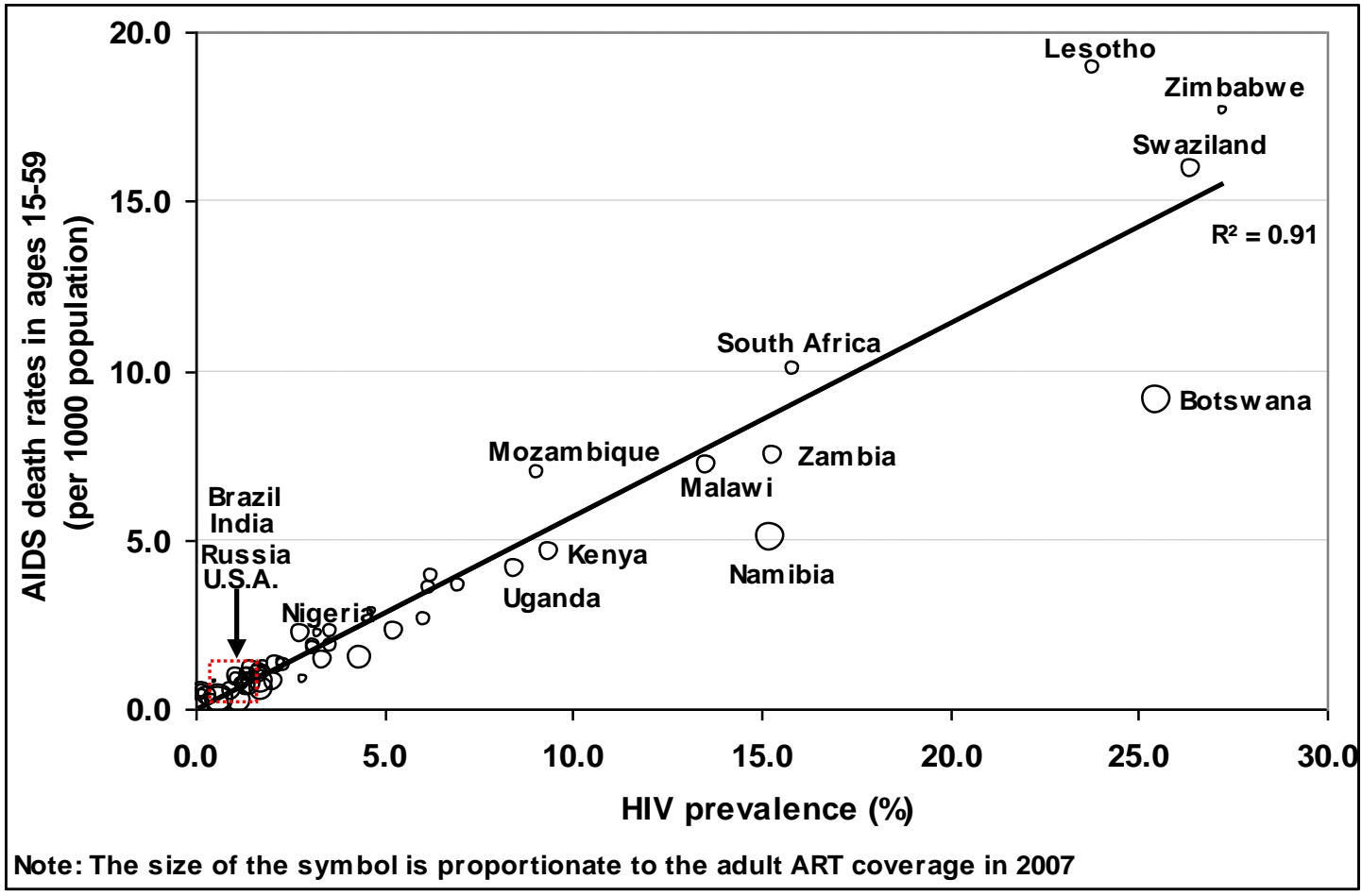

Source: United Nations 2009a (special tabulations). 
Figure 5. Estimated and Projected Deaths Due to AIDS by Region, 1980-2030

A. Numbers

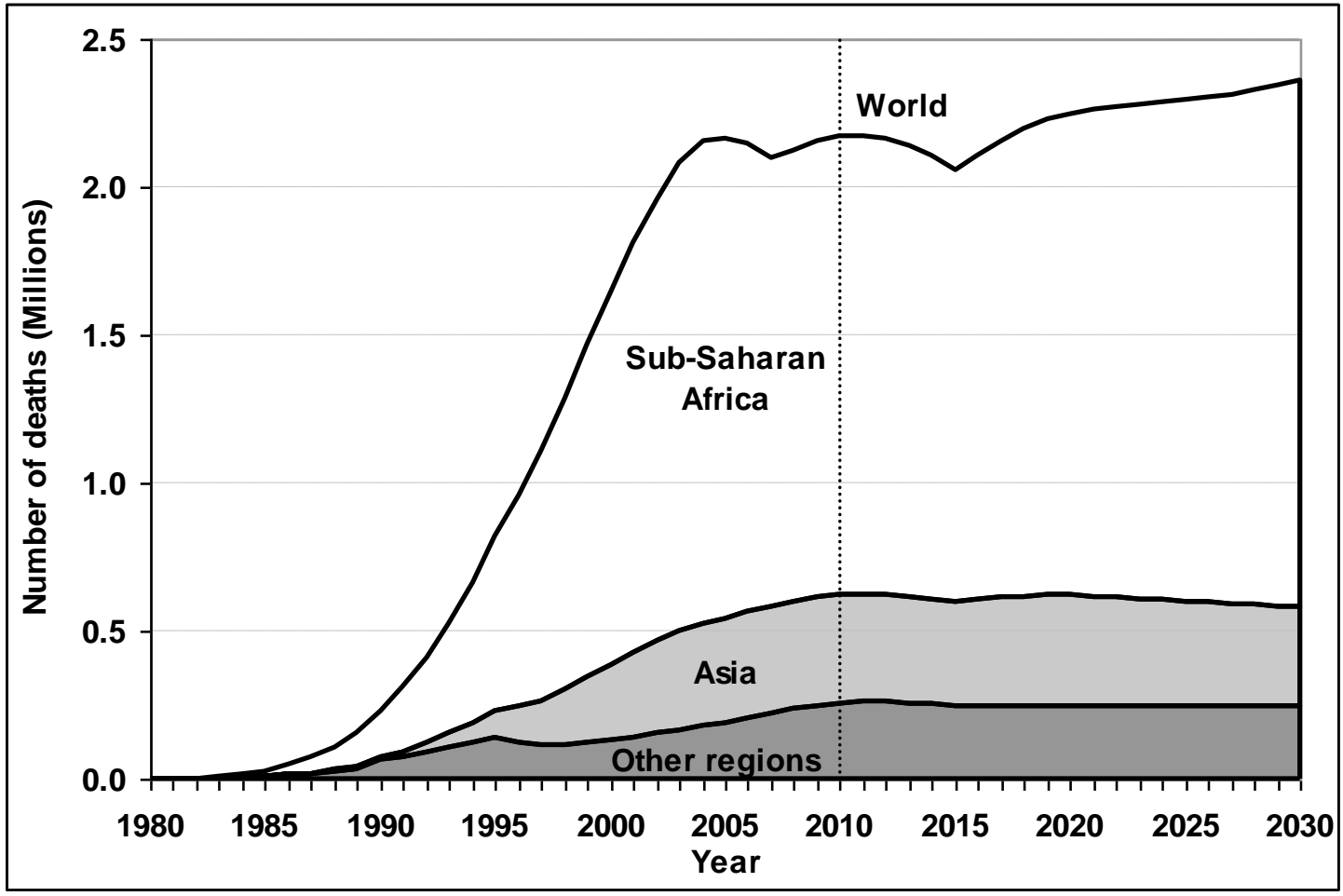

B. Percentages

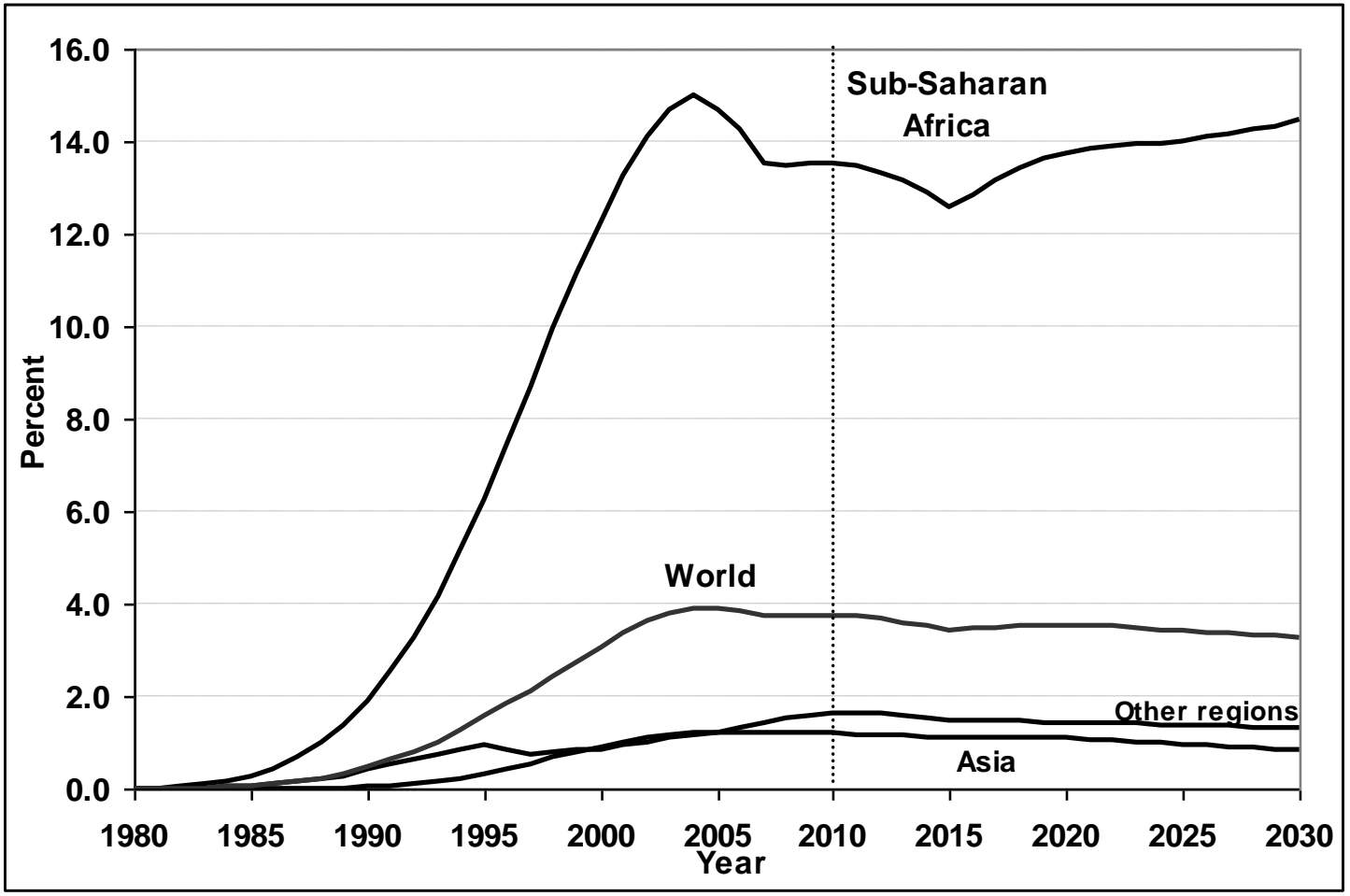

Source: United Nations 2009a (special tabulations and authors calculations). 
Figure 6. Estimated and Projected Deaths due to AIDS by Broad Age Group, 58 Countries, 1980-2030

A. Numbers

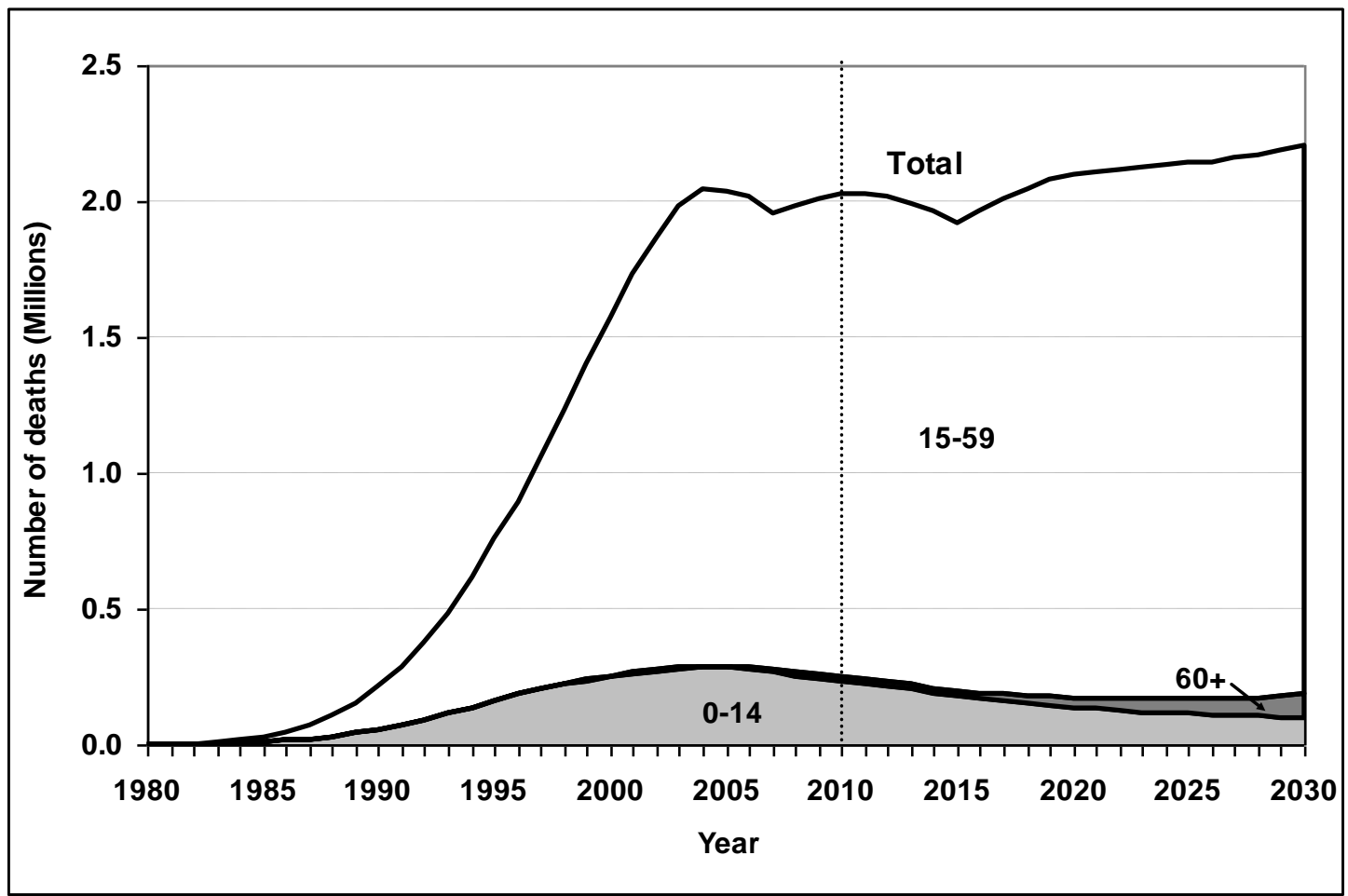

\section{B. Percentages}

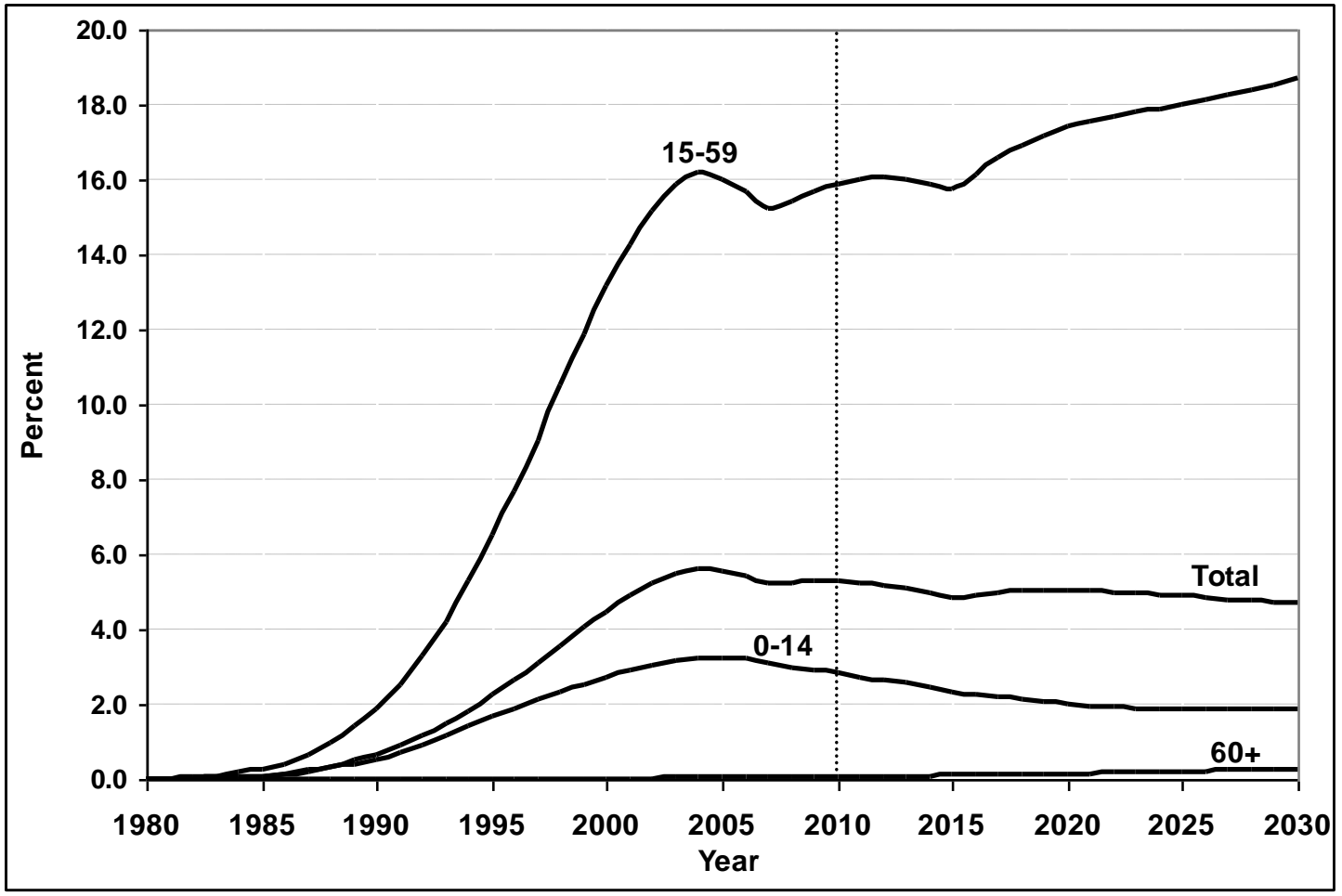

Source: United Nations 2009a (special tabulations). 
Figure 7. Percentage of Deaths due to AIDS in Age Group 15-59, Selected Countries, 1980-2030

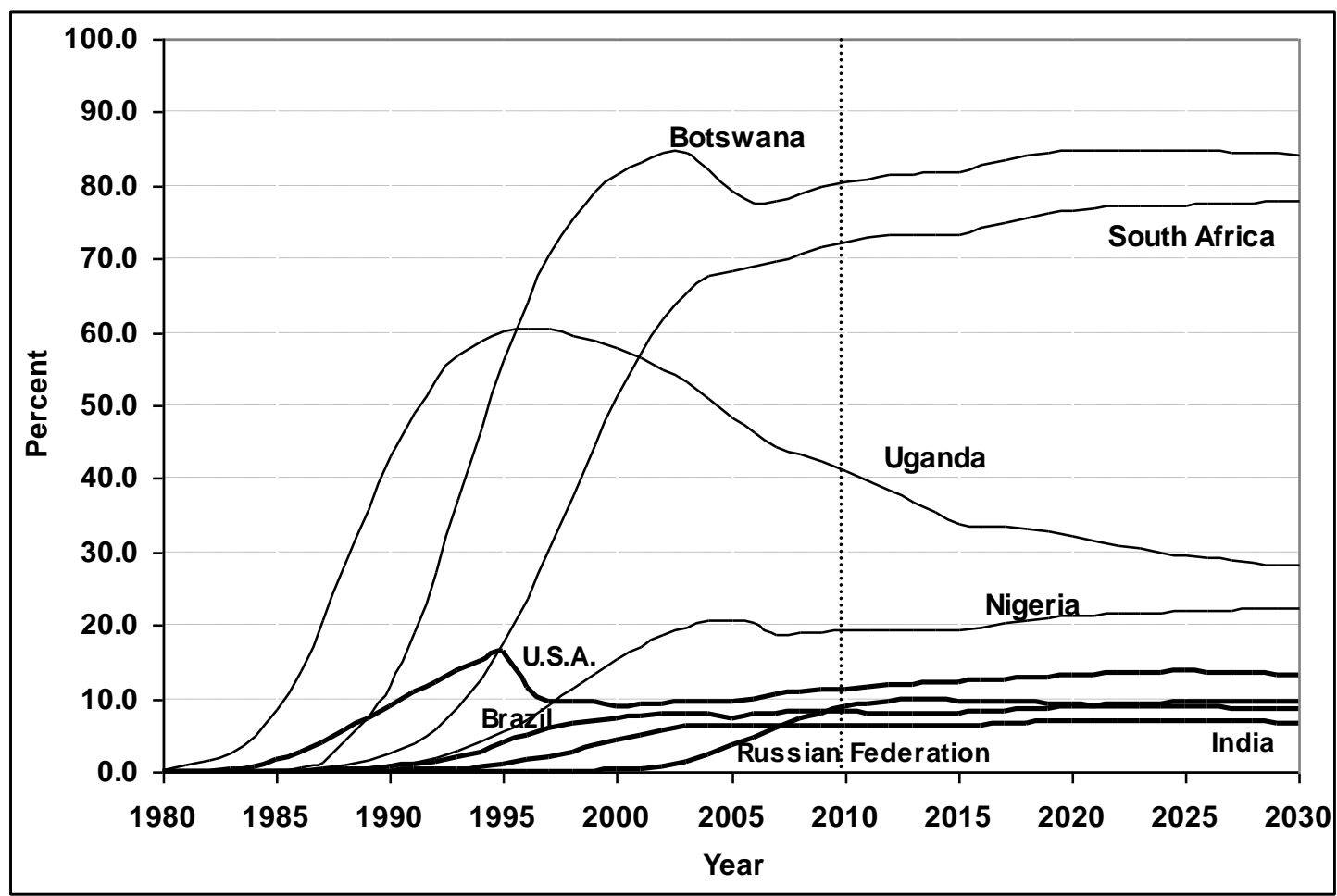

Source: United Nations 2009a (special tabulations). 
Figure 8. Life Expectancy at Age 15 with and without AIDS, 1980-2030 A. Selected Non-African Countries

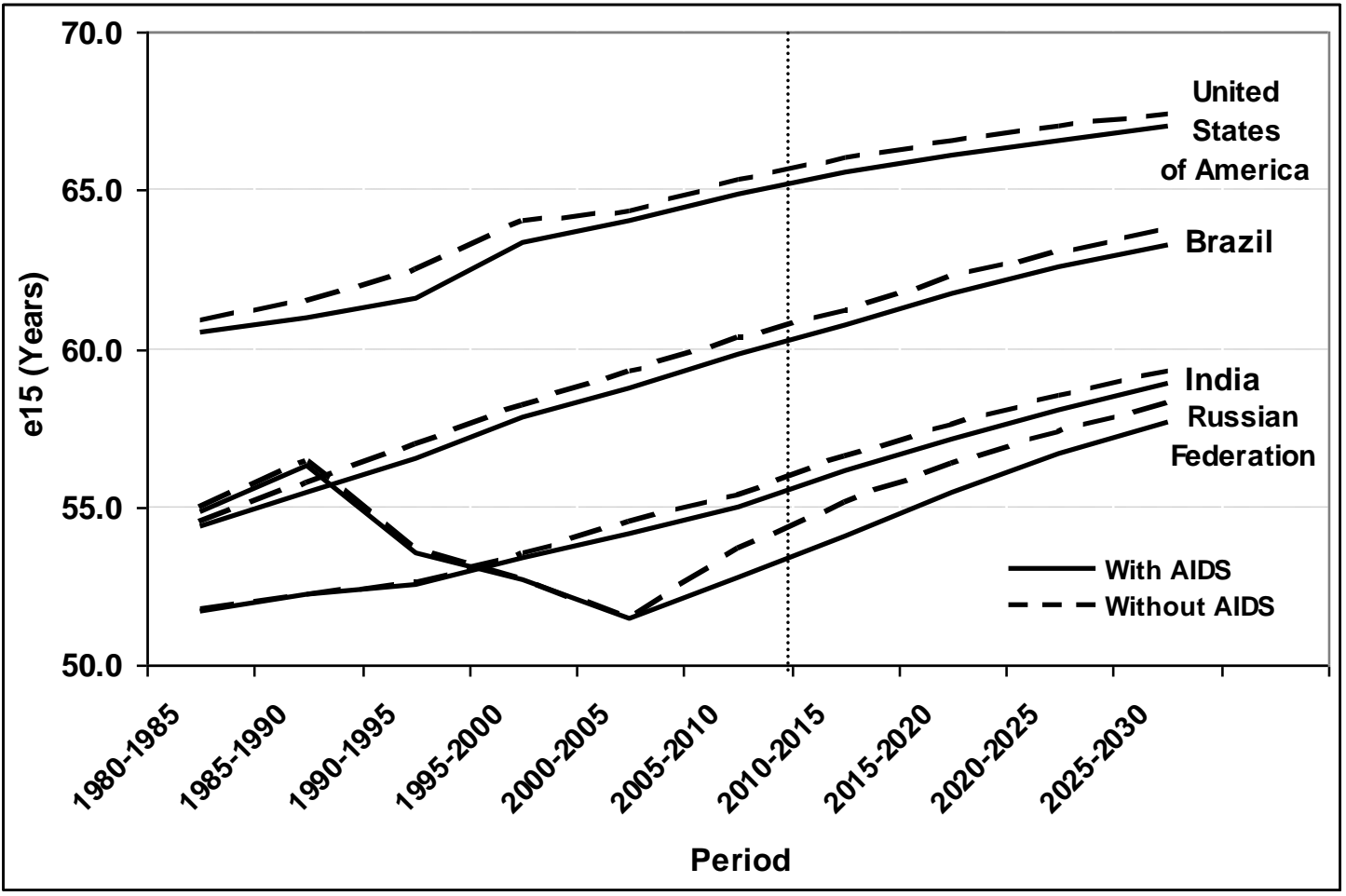

B. Selected African Countries

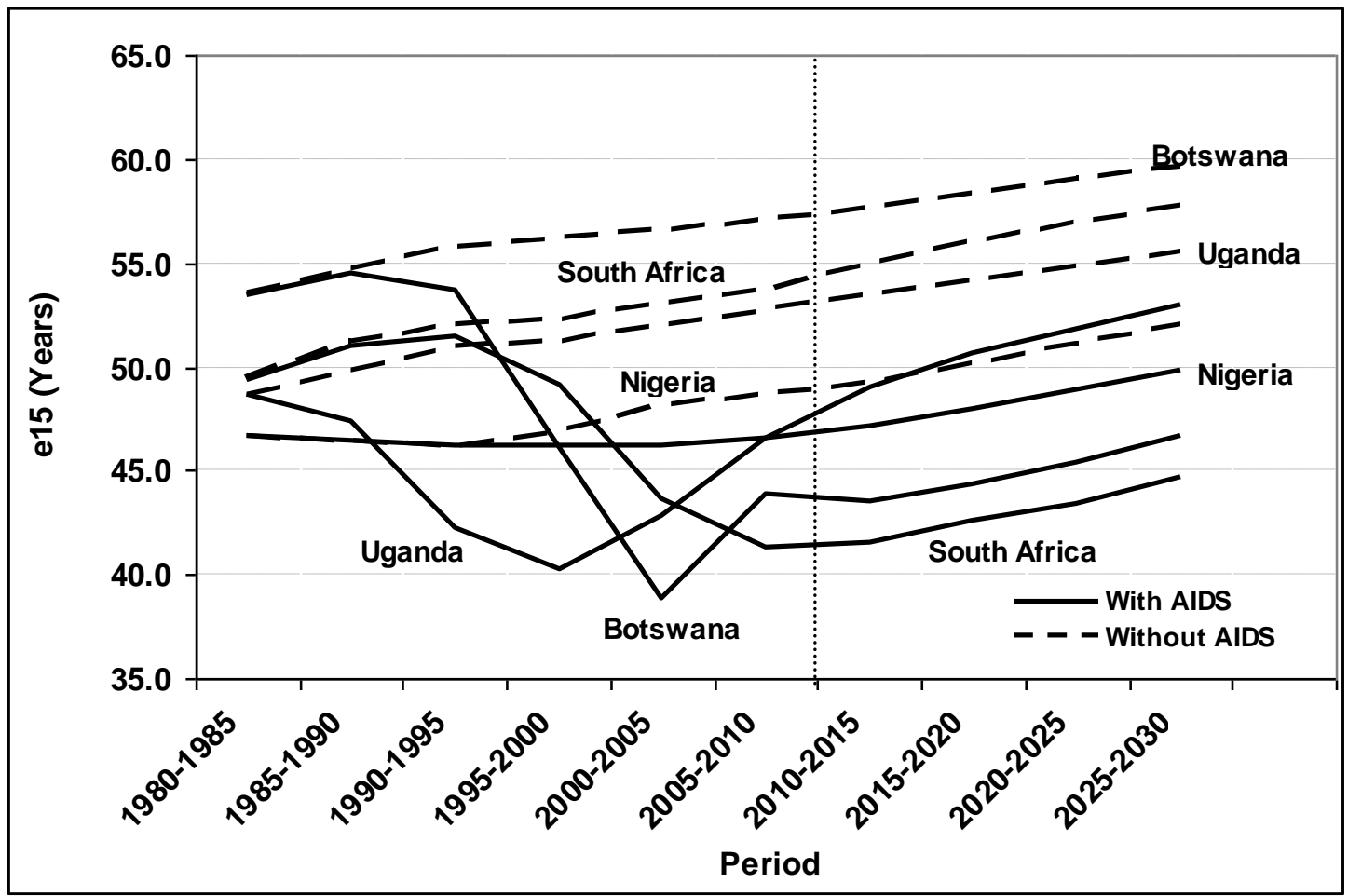

Source: United Nations 2009a. 
Figure 9. Change in Life Expectancy at Age 15 due to AIDS, Selected Countries, 1980-2030

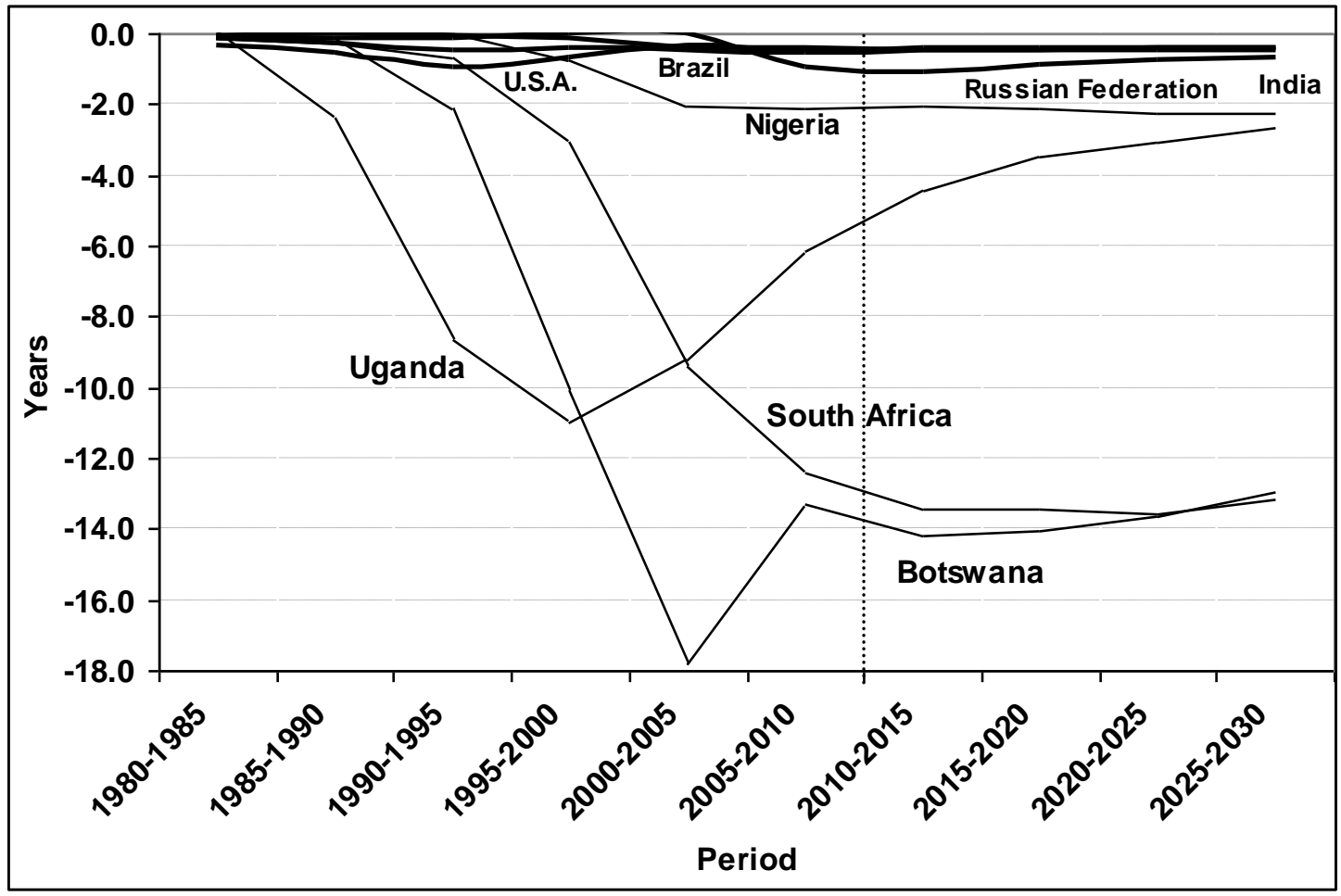

Source: United Nations 2009a. 
Figure 10. Absolute Difference in $e_{15}$ Levels, AIDS vs. No-AIDS Scenarios, 2005-2010 by HIV Prevalence among Adults Aged 15-49 in 2000

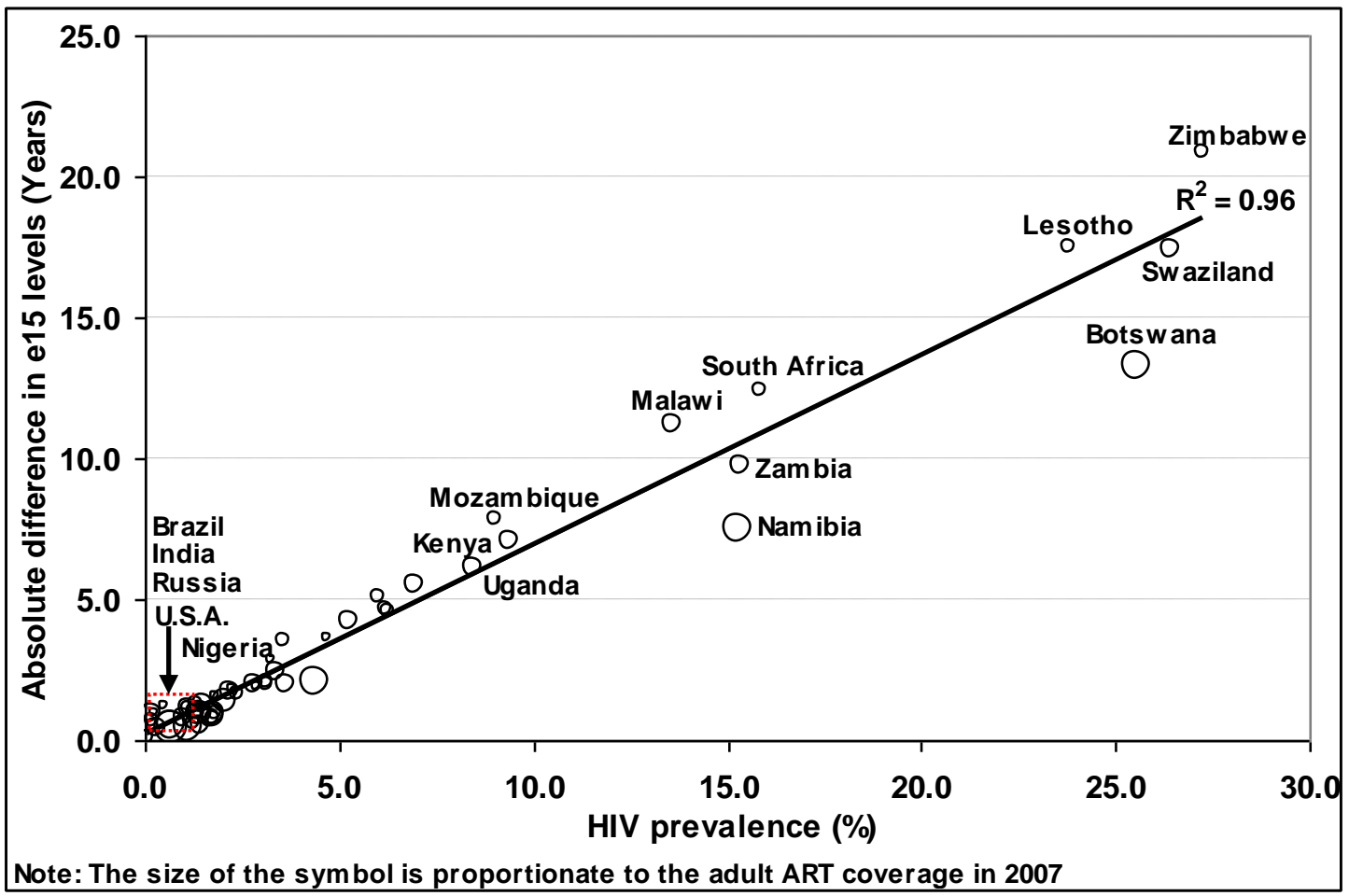

Source: United Nations 2009a (special tabulations). 


\section{Poverty, Gender, and Youth Working Papers}

If still in print, single copies of up to three working papers from 1989 through 2003 are available free of charge.

Beginning with the 2004 issues, working papers are no longer available in print format. Instead they are distributed electronically. As each new paper is completed, subscribers are notified by e-mail and a link to the paper is provided.

To subscribe to the Poverty, Gender, and Youth working paper e-mail notification list, or to obtain back issues from 1989 to 2003, please send your request to pgywp@ popcouncil.org.

PDFs of recent issues are available at www.popcouncil.org/publications/wp/index.html

2009

16 John Bongaarts, François Pelletier, and Patrick Gerland, "Global trends in AIDS mortality."

15 Bussarawan Teerawichitchainan and Sajeda Amin, "The role of abortion in the last stage of fertility decline in Vietnam."

14 Cynthia B. Lloyd and Paul C. Hewett, "Educational inequalities in the midst of persistent poverty:

Diversity across Africa in educational outcomes."

13 Wendy Baldwin and Judith Diers, "Demographic data for development in sub-Saharan Africa."

2008

12 Sajeda Amin and Lopita Huq, "Marriage considerations in sending girls to school in Bangladesh: Some qualitative evidence."

11 S. Chandrasekhar and Abhiroop Mukhopadhyay, "Multiple dimensions of urban well-being: Evidence from India"
10 Sajeda Amin and Luciana Suran, "Terms of marriage and time-use patterns of young wives: Evidence from rural Bangladesh."

9 John Bongaarts, Thomas Buettner, Gerhard Heilig, and François Pelletier, "Has the HIV epidemic peaked?"

8 Barbara S. Mensch, Paul C. Hewett, Richard Gregory, and Stephane Helleringer, "Sexual behavior and STI/HIV status among adolescents in rural Malawi: An evaluation of the effect of interview mode on reporting."

7 John Bongaarts, "Fertility transitions in developing countries: Progress or stagnation?"

2007

6 Cynthia B. Lloyd, "The role of schools in promoting sexual and reproductive health among adolescents in developing countries."

5 Ann Biddlecom, Richard Gregory, Cynthia B. Lloyd, and Barbara S. Mensch, "Premarital sex and schooling transitions in four subSaharan African countries." 
4 Sajeda Amin, John B. Casterline, and Laura Spess, "Poverty and fertility:

Evidence and agenda."

3 Bussarawan Teerawichitchainan and James F. Phillips, "Ethnic differentials in parental health seeking for childhood illness in Vietnam."

2 Zachary Zimmer, Kim Korinek, John Knodel, and Napaporn Chayovan, "Support by migrants to their elderly parents in rural Cambodia and Thailand: A comparative study."

1 Sharon Ghuman and Cynthia B. Lloyd, "Teacher absence as a factor in gender inequalities in access to primary schooling in rural Pakistan." 